\title{
Uterine Artery Doppler for Prediction of Amenorrhea in Women Desiring to use the Lactational menorrhea Method for Contraception
}

\author{
Alaa Al-Halaby ${ }^{1 *}$, Nehad Hosni ${ }^{1}$, Abd-Elhamid Shaheen ${ }^{1}$ and Mohamed Shawky ${ }^{2}$ \\ ${ }^{1}$ Department of Obstetrics and Gynecology, Menoufia University, Egypt \\ ${ }^{2}$ Department of Radiology, Faculty of Medicine, Menoufia University, Egypt
}

Submission: January 16, 2017; Published: February 07, 2018

"Corresponding author: Alaa Al-Halaby, Department of Obstetrics and Gynecology, Menoufia University, 25 Yasin Abdelghafar street, Shibin ElKom City, Menoufia governorate, Egypt, Tel:+201146256413; Email: alaa.halaby@yahoo.com

\begin{abstract}
Objective: to test the hypothesis whether uterine artery pulsatility index (PI) and resistance index (RI) at 6 weeks postpartum could predict amenorrhea in women wishing to use the lactational amenorrhea method (LAM) for contraception.

Methods: This prospective observational study included 840 lactating women with exclusive breastfeeding who were underwent uterine artery Doppler study at 6 weeks postpartum and followed for 6 months for the return of menstruation with women divided into two groups; the amenorrhea group $(n=384)$ and the menstruating group $(n=456)$. The primary outcome measure was the value of uterine artery PI and RI in the prediction of amenorrhea. Data was collected and tabulated.

Results: There was a highly significant difference between the two groups regarding the uterine artery PI and RI at 6 weeks postpartum $(\mathrm{p}<0.001)$. Uterine artery PI at a cut off value of $\geq 3.5$ (area under the curve; AUC .846, sensitivity $92 \%$ and specificity $84.4 \%$ ) and uterine artery RI at a cut off value $\geq 0.8$ (AUC .806, sensitivity $80 \%$ and specificity $82.2 \%$ ) are predictors of amenorrhea among women desiring to use the LAM by multiple logistic regression analysis.

Conclusion: Uterine artery Doppler studies is simple, non-invasive and could be a valuable tool to predict amenorrhea among women desiring postpartum contraception who are interested in the LAM. Larger studies are warranted to confirm our findings.

Keywords: Lactational amenorrhea method; Uterine artery doppler; Breastfeeding; Postpartum contraception

Abreviations: LAM: Lactational Amenorrhea Method; PI: Pulsatility Index; RI: Resistance Index; WHO: World Health Organization; ROC: Receiver Operator Characteristic
\end{abstract}

\section{Introduction}

The lactational amenorrhea method (LAM) is an effective physiological method for contraception. Suckling induces a reduction in gonadotrophin releasing hormone, luteinizing hormone and follicle stimulating hormone release, resulting in amenorrhea [1].

Exactly how the breastfeeding stimulus reduces pulsatile secretion of GnRH/LH is not clear. The role of prolactin remains uncertain as suckling releases both prolactin and suppresses GnRH release [2].

The woman should have another method of contraception when any of the three criteria of LAM-full or nearly full breastfeeding, amenorrhea, and below 6 months of age, no longer applies [3].

According to the Egyptian Demographic and Health Survey data, about $80 \%$ of Egyptian women breastfed for at least 6 months and 40\% breastfed for 15-18 months. Over half of breastfeeding mothers used no additional method of contraception [4].

LAM is a commonly used method in Egypt but, it is liable to discontinuation or violation of its criteria $[5,6]$.

The aim of this study was to test the hypothesis whether uterine artery pulsatility index (PI) and resistance index (RI) at 6 
weeks postpartum could predict amenorrhea in women wishing to use the LAM for contraception.

\section{Materials and Methods}

This prospective observational study was conducted in the department of Obstetrics and Gynecology in collaboration with the Radiology department at Menoufia University hospital, Menoufia governorate, Egypt in the period between October 2014 and October 2017.

All procedures performed in the current study involving human participants were in accordance with the ethical standards of the Menoufia Fcaulty of Medicine research ethical committee and with the 1964 Helsinki declaration and its later amendments. Informed consent was obtained from all participants prior to commencing the study.

Lactating sexually active women with amenorrhea who desired to use the lactational amenorrhea method for contraception were enrolled following thorough history taking, clinical examination and transvaginal ultrasound with assessment of uterine artery Doppler indices six weeks after delivery with subsequent follow up visits monthly for 6 months to trace the resumption of menstruation or persistence of amenorrhea. Motivated participants were encouraged to maintain continuous and exclusive breastfeeding throughout the entire follow up period. Data of breastfeeding was asked for at the monthly visit and collected at 6 months after delivery.

Non-exclusive or semi-exclusive breastfeeding, uterine or pelvic organic lesions, medical disorders and bleeding tendency were listed as exclusion criteria.

Uterine artery Doppler study was performed at the Radiology department using a Hitachi EUB-7000 ultrasound machine (Hitachi, Japan) by $7 \mathrm{MHz}$ transvaginal probe. Examinations were done by a single operator with previous experience in Doppler ultrasound to avoid inter-observer variability. Pulsed wave Doppler was applied at a sampling gate of $2 \mathrm{~mm}$ with the angle of insonation at less than $30^{\circ}$. Pulsatility index (PI) and Resistance index (RI) were determined automatically of the right and left uterine arteries were measured with the mean of two uterine arteries recorded following three similar waveforms. Participants were instructed to avoid the intake of non-steroidal anti-inflammatory drugs 24 hours before the examination. All the ultrasound Doppler studies were measured between 8:00 and 11:00 am to eliminate diurnal variation.

Menstrual calendars were used to record the days on which women suffered bleeding as recommended by the World Health Organization (WHO). Menses was defined either as 2 days of consecutive bleeding and/or the woman's recognition that a menses had occurred.

For better interpretation of results, we divided participants into two groups based on resumption of menstruation during the 6 months of follow up: o $\quad$ Group 1 (Amenorrhea group): included 384 lactating participants without menstruation after exclusion of pregnancy via blood test done monthly during the six months follow up period.

o $\quad$ Group 2 (Menstruating group): included 456 lactating participants with reported menstruation who were advised to start immediately another method of contraception as progestin only methods or intrauterine device according to their preferences.

Outcome measures:

a. Uterine artery Doppler indices 6 weeks after delivery.

b. Correlation between uterine artery PI and RI and subsequent amenorrhea for the next 6 months.

\section{c. Statistical analysis}

Data was statistically analyzed by computer using SPSS version 22(SPSS Inc, Chicago, IL, USA). Parametric data was expressed as means and standard deviations with student t-test and Mann Whitney test were used to compare between the two groups where appropriate, while non-parametric data was expressed as number and percent with Chi-squared test was used to compare categorical outcome. P value $\leq 0.05$ was considered to be significant. Multiple logistic regression was done to determine predictors of amenorrhea. Receiver operator characteristic (ROC) curve was done to determine cut-off value, sensitivity and specificity of PI and RI in the resumption of menstruation.

Results

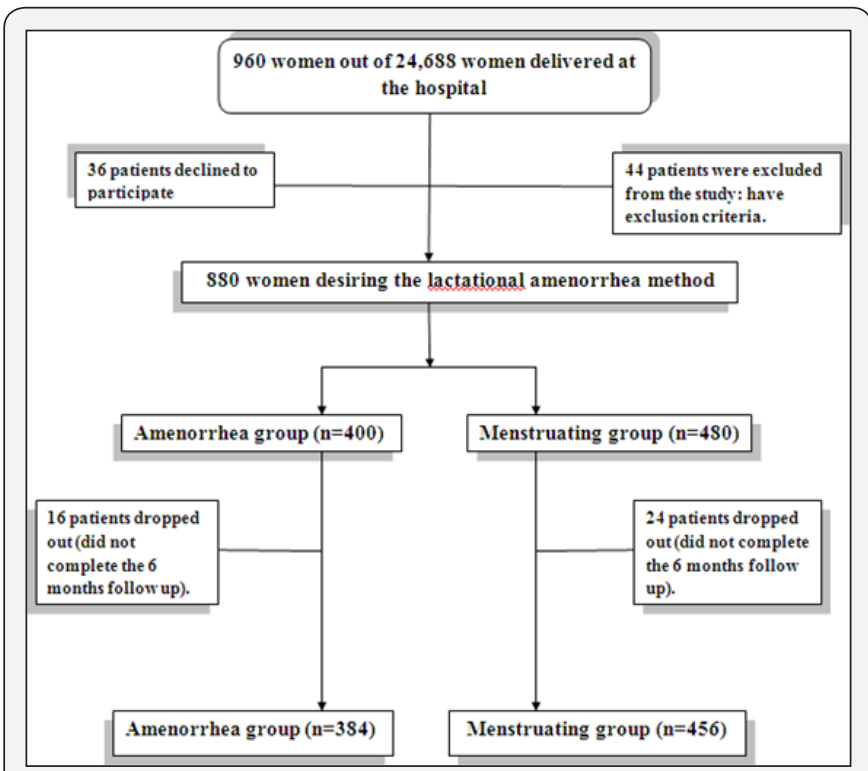

Figure 1: Flow diagram of recruitment and retention of patients in the study.

Out of 24688 women delivered at the hospital during the study period, 960 women were enrolled with 80 women have 
exclusion criteria or declined to participate in the study. 880 women desiring the lactational amenorrhea method with 40 women dropped out during the follow up period and 840 completed the study; 384 in the amenorrhea group and 456 in the menstruating group (Figure 1).
There was no significant difference between the two groups regarding the age, parity, body mass index, hemoglobin concentration (at 6 weeks \& 6 months), work status, infant gender, number of feeds at night, breastfeeding pattern and pregnancy rate within the 6 months $(p>0.05)$ as depicted in Table 1.

Table 1: Participants' characteristics.

\begin{tabular}{|c|c|c|c|c|}
\hline & Amenorrhea Group $(n=384)$ & Menstruating Group $(n=456)$ & Student t-Test & P-value \\
\hline Age (year) & $31.2 \pm 4.1$ & $30.9 \pm 4.6$ & 0.99 & $>0.05$ \\
\hline parity & $2.3 \pm 1.3$ & $2.2 \pm 1.2$ & $1.16^{*}$ & $>0.05$ \\
\hline Body mass index $\left(\mathrm{Kg} / \mathrm{m}^{2}\right)$ & $23.8 \pm 3.8$ & $24.1 \pm 3.2$ & 1.24 & $>0.05$ \\
\hline \multicolumn{5}{|c|}{ Hemoglobin(gm/dl) } \\
\hline -At 6 weeks & $10.9 \pm 1.28$ & $10.8 \pm 1.34$ & 0.69 & $>0.05$ \\
\hline -At 6 months & $10.8 \pm 1.33$ & $10.7 \pm 1.32$ & 0.58 & $>0.05$ \\
\hline \multicolumn{5}{|c|}{ Work status } \\
\hline -Working & 180 & 210 & & \\
\hline -Housewife & 204 & 246 & 0.03 & $>0.05$ \\
\hline \multicolumn{5}{|c|}{ Infant gender } \\
\hline -Male & 184 & 216 & 0.01 & $>0.05$ \\
\hline -Female & 200 & 240 & & \\
\hline \multicolumn{5}{|c|}{ Number of feeds at night: } \\
\hline$<5$ & 98 & 116 & 0.001 & $>0.05$ \\
\hline$\geq 5$ & 286 & 340 & & \\
\hline \multicolumn{5}{|c|}{ Breastfeeding pattern: } \\
\hline -Exclusive & 294 & 356 & 0.19 & $>0.05$ \\
\hline -Semiexclusive & 90 & 100 & & \\
\hline Pregnancy rate during the 6 months & $3(0.78 \%)$ & $4(0.87 \%)$ & 0.05 & $>0.05$ \\
\hline
\end{tabular}

*Mann Whitney test.

Table 2: Uterine artery Doppler indices.

\begin{tabular}{|l|c|c|c|c|}
\hline & Amenorrhea group (n=384) & Menstruating group (n=456) & $\begin{array}{c}\text { Mann Whitney } \\
\text { test }\end{array}$ & P-value \\
\hline Pulsatility index (PI): & $3.8 \pm 0.2$ & $2.3 \pm 1.1$ & 26.3 & $<0.001$ \\
\hline Resistance index (RI): & $0.92 \pm 0.06$ & $0.66 \pm 0.04$ & 74.8 & $<0.001$ \\
\hline
\end{tabular}

Table 3: Multiple logistic regression analysis of participants' characteristics and subsequent amenorrhea.

\begin{tabular}{|c|c|c|c|c|c|}
\hline & AUC & Sensitivity & Specificity & Cut -off value & P-value \\
\hline Age & 0.504 & $58 \%$ & $62 \%$ & - & $>0.05$ \\
\hline BMI & 0.566 & $54 \%$ & $58 \%$ & - & $<0.05$ \\
\hline Uterine PI & 0.846 & $92 \%$ & $84.40 \%$ & 8.5 & $<0.001$ \\
\hline Uterine RI & 0.806 & $80 \%$ & $54 \%$ & - & $>0.001$ \\
\hline Parity & 0.542 & $52 \%$ & $58 \%$ & - & $>0.05$ \\
\hline Work status & 0.525 & $51 \%$ & $56 \%$ & - & $>0.05$ \\
\hline Infant gender & 0.536 & $52 \%$ & $54 \%$ & - & $>0.05$ \\
\hline Number of feeds at night & 0.512 & $50 \%$ & $57 \%$ & - & $>0.05$ \\
\hline Breastfeeding pattern & 0.566 & $55 \%$ & & -0.05 \\
\hline
\end{tabular}

BMI: Body Mass Index, PI: Pulsatility Index, RI: Resistance Index 


\section{Journal of Gynecology and Women's Health}

There was a highly significant difference between the two groups regarding the uterine artery PI and RI $(\mathrm{p}<0.001)$ as revealed in Table 2 (Figures $2 \& 3$ ).

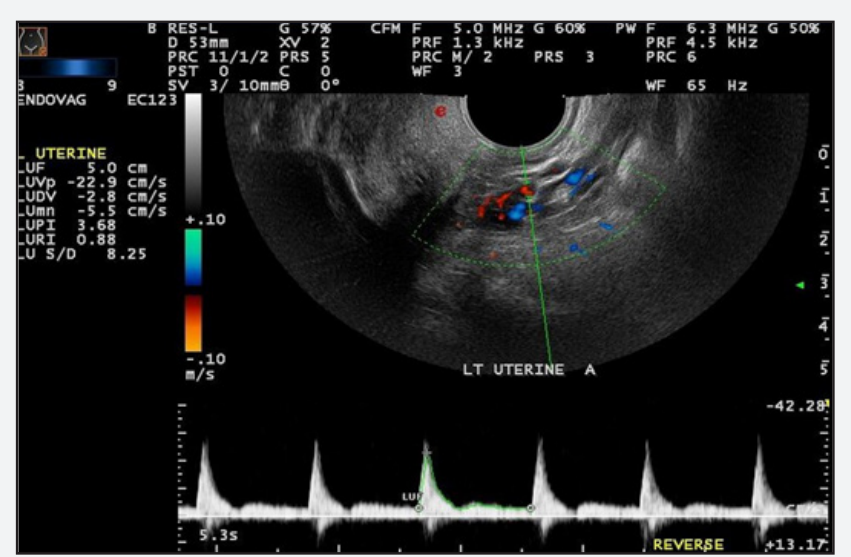

Figure 2 : High values of uterine artery $\mathrm{PI}$ and $\mathrm{RI}$ in P3, 30 years woman in the amenorrhea group.

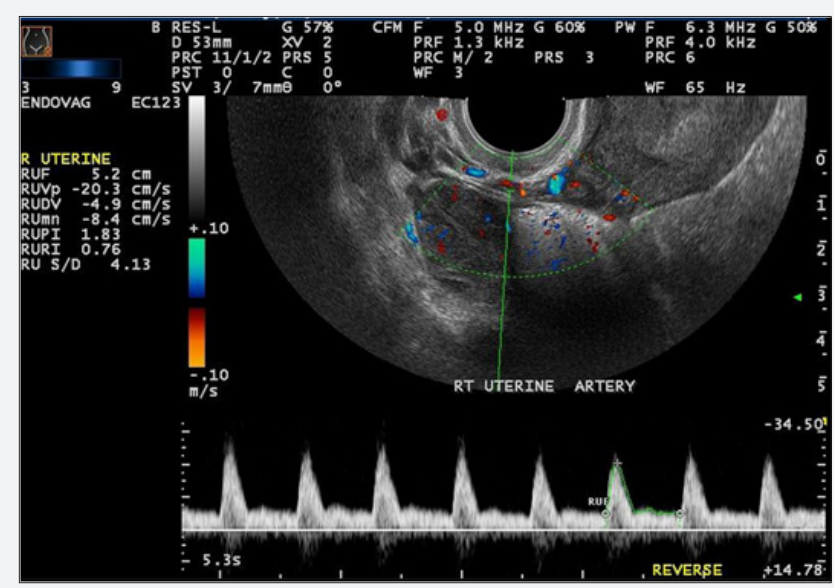

Figure 3 : Average values of uterine artery $\mathrm{PI}$ and $\mathrm{RI}$ in $\mathrm{P} 2,28$ years woman in the menstruating group.

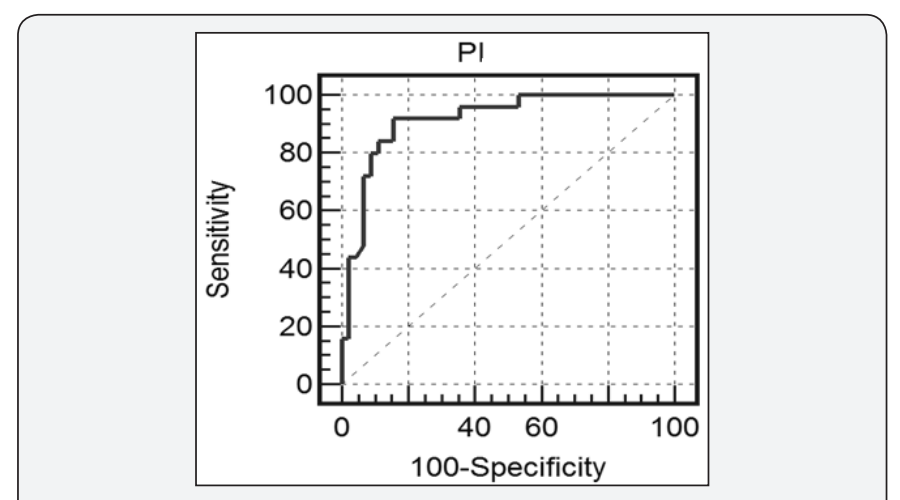

Figure 4 : The ROC curve of uterine artery PI.

Uterine artery PI at a cut off value of $\geq 3.5$ (area under the curve; AUC .846, sensitivity $92 \%$ and specificity $84.4 \%$ ) as demonstrated in Figure 4, and uterine artery RI at a cut off value $\geq 0.8$ (AUC .806, sensitivity $80 \%$ and specificity $82.2 \%$ ) as demonstrated in Figure 5, are predictors of amenorrhea among women desiring to use the lactational amenorrhea method by multiple logistic regression analysis as shown in Table 3.

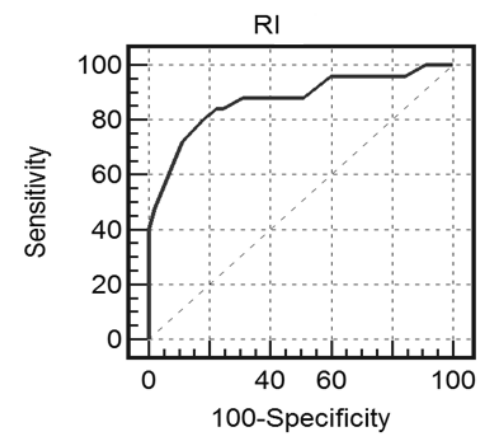

Figure 5: The ROC curve of uterine artery RI.

\section{Discussion}

To the authors' knowledge, this the first study to assess the uterine artery Doppler indices at six weeks postpartum to predict the occurrence of amenorrhea among lactating women desiring to use the LAM. Uterine artery PI at a cut off value of $\geq 3.5$ (area under the curve; AUC .846, sensitivity 92\% and specificity $84.4 \%$ ) and uterine artery RI at a cut off value $\geq 0.8$ (AUC .806, sensitivity $80 \%$ and specificity $82.2 \%$ ) are predictors of amenorrhea.

Only one previous study in the literature was conducted to predict subsequent amenorrhea among 80 lactating women with exclusive breastfeeding at the third month postpartum via measuring estradiol, basal and post suckling prolactin hormonal levels and concluded that estradiol and post suckling prolactin at cut off values of $190 \mathrm{pmol} / \mathrm{L}$ and $119.85 \mathrm{ng} / \mathrm{ml}$ respectively were predictors for the time of the return of menstruation between the 3rd and 12th postpartum months [7].

LAM is cost-effective for infant feeding in low-resource countries like Egypt, as breastfeeding alone provides wellbalanced nutrition and fluid intake to infants during the first 6 months of life. In addition, breast milk is considered a healthier and cheaper option than formula or other substitutes for infants [8].

The overall acceptance of LAM among Egyptian women was around $84 \%$ as demonstrated in a previous study [9].

The use of more effective contraceptive method during the first 6 months after delivery is increased when counselling was provided earlier during the prenatal and immediate postpartum time periods [10]. Also, although modern and long acting reversible contraceptive methods are available, their usage by women in developing and low-resource settings is low as reported by a recent large scale study that was conducted in Asia including 36,687 women in the postpartum period [11].

Motivated women in Egypt who desire to use the LAM should be properly counselled regarding the criteria and effectiveness of LAM through personal interviews and broadcasting media [6]. 
The rate of unintended pregnancy among women in the amenorrhea group using the LAM in the current study was 3/ $384(0.78 \%)$.

Previous studies of the contraceptive effect of LAM have reported cumulative 6- month life-table perfect-use pregnancy rates of $0.5-1.5 \%$ among women who relied only on LAM [1214]. A Cochrane review published in 2015 estimated the typical use failure rate of LAM to be about $0.45-7.5 \%$ [15].

The strength of this study resides in being the first to use the initial uterine artery Doppler indices for prediction of amenorrhea among lactating women in addition to the larger number of included participants.

Non-repetition of uterine artery Doppler indices during the follow-up period and non-measurement of hormones constitutes unintended limitations of this study.

Future research should explore the validity of uterine artery Doppler indices for prediction of extended amenorrhea in women using the LAM after 6 months from delivery.

\section{Conclusion}

Uterine artery Doppler studies is simple, non-invasive and could be a valuable tool to predict amenorrhea among women desiring postpartum contraception who are interested in the LAM. Larger studies are warranted to confirm our findings.

\section{References}

1. Vekemans M (1997) Postpartum contraception: the lactational amenorrhea method. Eur J Contracept Reprod Health Care 2(2): 105111.

2. McNeilly AS (2001) Neuroendocrine changes and fertility in breastfeeding women. Prog Brain Res 133: 207-214.

3. Labbok MH (2015) Postpartum Sexuality and the Lactational Amenorrhea Method for Contraception. Clin Obstet Gynecol 58(4): 915-927.
4. Khella AK, Fahim HI, Issa AH, Sokal DC, Gadalla MA (2004) Lactational amenorrhea as a method of family planning in Egypt. Contraception 69(4): 317-322.

5. Afifi M (2007) Lactational amenorrhoea method for family planning and women empowerment in Egypt. Singapore Med J 48(8): 758-762.

6. Afifi M (2008) Lactational Amenorrhoea and Modern Contraceptives Use among Nursing Women in Egypt 2003. Oman Med J 23(2): 72-77.

7. Valdés P, Orellana JJ (2007) Post suckling prolactin and estradiol levels as predictors of the time of appearance of the first post partum menstruation. Rev Med Chil 135(4): 419-426.

8. Kennedy KI, Kotelchuck M (1998) Policy considerations for the introduction and promotion of the lactational amenorrhea method: advantages and disadvantages of LAM. J Hum Lact 14(3): 191-203.

9. Makhlouf AM, Salah M, Shaaban MM, Labbo KM (1997) A clinical study of lactational amenorrhea method for family planning in Egypt. Contraception 1: 63-72.

10. Zapata LB, Murtaza S, Whiteman MK, Jamieson DJ, Robbins CL, et al. (2015) Contraceptive counseling and postpartum contraceptive use. Am J Obstet Gynecol 212(2):171.e1-8.

11. Pasha O, Goudar SS, Patel A, Garces A, Esamai F, et al. (2015) Postpartum contraceptive use and unmet need for family planning in five lowincome countries. Reprod Health 12(Suppl 2): S11.

12. Pérez A, Labbok MH, Queenan JT (1992) Clinical study of the lactational amenorrhoea method for family planning. Lancet 339(8799): 968-970.

13. Ramos R, Kennedy KI, Visness CM (1996) Effectiveness of lactational amenorrhoea in prevention of pregnancy in Manila, the Philippines: non-comparative prospective trail. BMJ 313(7062): 909-912.

14. Labbok MH, Hight-Laukaran V, Peterson AE, Fletcher V, von Hertzen $H$, et al. (1997) Multicenter study of the lactational amenorrhea method (LAM): efficacy, duration, and implications for clinical application. Contraception 55(6): 327-336.

15. Van der Wijden C, Manion C (2015) Lactational amenorrhoea method for family planning. Cochrane Database Syst Rev 10: CD001329.

\section{Your next submission with Juniper Publishers will reach you the below assets}

- Quality Editorial service

- Swift Peer Review

- Reprints availability

- E-prints Service

- Manuscript Podcast for convenient understanding

- Global attainment for your research

- Manuscript accessibility in different formats

( Pdf, E-pub, Full Text, Audio)

- Unceasing customer service

Track the below URL for one-step submission https://juniperpublishers.com/online-submission.php 